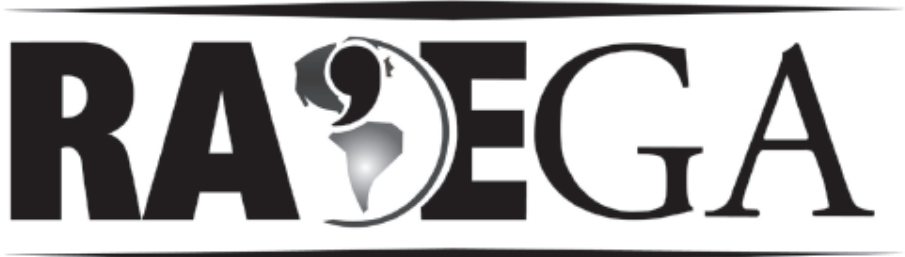

O ESPAÇO GEOGRÁFICO EM ANÁLISE

\title{
A QUALIDADE AMBIENTAL URBANA NA LEGISLAÇÃO MUNICIPAL: EXEMPLO DO PLANO DIRETOR DE ARAÇATUBA-SP ${ }^{1}$
}

\section{URBAN ENVIRONMENTAL QUALITY IN MUNICIPAL LAW: THE MASTER PLAN FOR EXAMPLE ARAÇATUBA-SP}

\author{
Cíntia Minaki ${ }^{2}$ \\ Margarete Cristiane de Costa Trindade Amorim ${ }^{3}$
}

\section{RESUMO}

A qualidade ambiental é um dos aspectos fundamentais para se caracterizar a qualidade de vida nas cidades. As atividades antrópicas interferem sobre os processos ambientais, causando diversos impactos que devem ser minimizados. Cumpre à legislação municipal impor fundamentos teóricopráticos proporcionais à dimensão dos problemas observados localmente. Acerca dessa questão, o trabalho teve como objetivo discutir o reconhecimento da qualidade ambiental urbana na legislação municipal, especificamente no Plano Diretor, analisando o caso de Araçatuba-SP. Foi possível observar que, em vários aspectos, tal norma se distancia da realidade urbana.

PALAVRAS-CHAVE: Qualidade ambiental urbana; Plano Diretor; Araçatuba-SP.

\footnotetext{
${ }^{1} \mathrm{O}$ artigo compõe parte dos estudos teóricos de um projeto financiado pela Fundação de Amparo à Pesquisa do Estado de São Paulo (FAPESP).

2 Doutoranda da Pós-Graduação em Geografia da Universidade Estadual Paulista Júlio de Mesquita Filho, Presidente Prudente. SP, Brasil. cminaki@gmail.com

${ }^{3}$ Bolsista Produtividade do CNPq. Prof ${ }^{a}$. Dr ${ }^{2}$. da Pós-Graduação em Geografia da Universidade Estadual Paulista Júlio de Mesquita Filho, Presidente Prudente, SP, Brasil. mccta@fct.unesp.br
} 


\section{ABSTRACT}

Environmental quality is a fundamental issue in order to characterize quality of life in the cities. The human activities interfere in environmental processes, causing impacts that must be minimized. It is the task of municipal laws to impose theoretic and practical foundations appropriated to the dimension of local problems. In this sense, the goal of this work was to propose a discussion about the recognition of environmental quality in municipal law, especially in the Municipal Master Plan of Araçatuba, city located in the state of São Paulo. It was possible to observe that in many aspects this law is far away from urban reality.

KEYWORDS: Urban environmental quality; Municipal Master Plan; Araçatuba-SP.

\section{INTRODUÇÃO}

A qualidade ambiental é um dos aspectos fundamentais para se caracterizar a qualidade de vida nas cidades. Entretanto, é uma abordagem específica entre tantas outras possibilidades de avaliar os espaços urbanos sob esse enfoque. Adotá-la significa buscar compreender as condições ambientais que se expressam por meio de indicadores. Esses indicadores cumulados podem compor uma avaliação objetiva ou subjetiva, sendo inseridos em metodologias, cuja diversidade se traduz em muitas hipóteses de trabalho.

Anterior ao modo de vida urbano, discutir a qualidade ambiental talvez não fosse uma necessidade como se entende atualmente. $O$ desenvolvimento industrial e as frequentes práticas inadequadas de expansão territorial urbana culminaram com ações reiteradas de sobrevivência e de desenvolvimento econômico, que interferiram sobre os processos ambientais. As modificações continuam ocorrendo, porém se torna necessário minimizar os impactos decorrentes dessa contínua expansão.

Nucci (2010) delimitou as possíveis origens dos estudos da paisagem. Nestes, Beck e Schoenwaldt ${ }^{4}$ (1999 apud NUCCI, 2010, p. 14) destacam a notória contribuição de Alexander von Humboldt (1769-1859) ao buscar entender os nexos dos fenômenos naturais já conhecidos, e ao introduzir o conceito científico de paisagem, importando-se secundariamente, com as

\footnotetext{
${ }^{4}$ BECK, H.; SCHOENWALDT, P. O último dos grandes. Alexander von Humboldt. Bonn: Inter Nationes, 1999, 48p.
} 
descobertas de novas espécies. Posteriormente, nomes como Troll (1939), Bertrand (1972), Sotchava (1977) e Tricart (1977), contribuíram para a crítica e desenvolvimento do conceito, constituindo referências para o histórico da Ciência da Paisagem.

A influência da Teoria Geral dos Sistemas na análise da paisagem ocorreu, sobretudo, na segunda metade do século XX, e o conceito de geossistema, foi concebido como uma associação do sistema à paisagem ${ }^{5}$, utilizado inicialmente por Stoddart (1969) e Neff (1969), sendo incorporado pelos estudiosos da Ciência da Paisagem (NUCCl, 2010, p. 15).

A Ecologia da Paisagem, escola criada por Troll (1939), e propagada nas décadas seguintes, é o "resultado de uma abordagem holística adotada por geógrafos, ecologistas, planejadores da paisagem, etc. procurando uma ponte entre os sistemas naturais, agrícolas e urbanos." (NUCCl, 2010, p. 17). Sua aceitação se exemplifica por algumas iniciativas da Alemanha, na década de 1970, ao criar cadeiras nas universidades, com temas condizentes ao entendimento dessa escola. Entretanto, houve opiniões contrárias à Ecologia e ao seu método integrador ( $\mathrm{NUCCl}, 2010$, p. 15 e 17).

Os estudos iniciais da paisagem foram, portanto, dotados da espontaneidade da observação humana, alcançando amplitude significativa, mas ainda não consensual em sua interpretação científica. $O$ vínculo dessa exploração conceitual com o surgimento de uma Ciência da Paisagem, demonstrou não só a busca pela autonomia científica do objeto de estudo, como também incorporou a noção de dinamicidade frequentemente omitida.

O Planejamento da Paisagem é atualmente, um importante recurso unificador de aspectos socioeconômicos e ambientais aplicável às áreas urbanas (NUCCl, 2010, p. 20). Através dessa ferramenta é possível ultrapassar a abstração em torno do tratamento dos recursos ambientais na cidade, que é um produto da ação humana e, via de regra, causador de impactos prejudiciais aos seus habitantes e à natureza. Por isso, acredita-se que a qualidade ambiental seja uma meta a ser cumprida dentro do Planejamento da Paisagem.

\footnotetext{
${ }^{5}$ Para mais informações, consultar a obra: PASSOS, M. M. dos. Biogeografia e Paisagem. Presidente Prudente: Edição do autor, 1988. 278p.
} 
Essa temática quando tratada pela legislação parece possuir um pressuposto lógico diferente daquele presente nos estudos científicos, podendo-se complementar com o entendimento de Kamp et al. (2003, p. 06), ao dizerem que, "(...) the manifestation of and context in which environmental quality is used in research and policymaking is seldom uniform". Essa ausência de consenso também ocorre dentro do meio acadêmico, e sob esse aspecto, Szalai $^{6}$ (1980 apud Kamp et al. 2003, p. 06) conclui que quando se lida com um conceito em desenvolvimento, é normal a falta de uniformidade.

Estes autores apresentaram algumas definições de qualidade ambiental, entre outros termos que são comumente utilizados como sinônimos. Aproveitase deste estudo, a definição de $\operatorname{RIVM}^{7}$ (2002; workshop livability 2002): "environmental quality can be defined as an essential part of the broader concept of 'quality of life', the basic qualities such as health and safety in combination with aspects such as cosiness and attractiveness." (KAMP et al., 2003, p. 07).

Longe de entendê-lo como um conceito fechado, acredita-se ainda que, a qualidade ambiental deve ser compreendida como um indicador da qualidade de vida, na qual as condições ambientais sobrepõem-se às condições infraestruturais da área em análise. Essa noção não fica tão evidente no conceito em questão, que propõe a combinação entre tais condições.

Por outro lado, a qualidade de vida tem um tratamento amplo nos seguintes dizeres:

[...] life quality refers to the degree of excellence or satisfactory character of life. A person's existential state, well-being, satisfaction with life is determined on the one hand by exogenous ('objective') facts and factors of his life and on the other hand by the endogenous ('subjective') perception and assessment he has of theses fact and factors, of life and of himself. (SZALAI, 1980 apud KAMP et al., 2003, p. 07).

O avanço dos estudos ambientais e a propagação de subtemas fundamentais para a articulação em grandes escalas evidenciam necessidades como as de diálogo entre os mecanismos públicos e privados. Desde que se

\footnotetext{
${ }^{6}$ SZALAI, A.The meaning of comparative research on the quality of life. In: SZALAI, A., ANDREWS, F. (Ed.). The Quality of Life. Sage Beverly Hills, CA, 1980. p. 7-24.

7 RIVM - National Institute for Public Health and the Environment.
} 
reconheça a cidade como um produto da intervenção antrópica já consolidado, é preciso criar meios para que os efeitos contra a natureza e contra a própria sociedade sejam reduzidos.

Nesse sentido, a legislação municipal surge como um fundamento que deve ser proporcional à dimensão dos problemas observados localmente. Instrumentos normativos como o Plano do Município e o Plano Diretor podem fornecer subsídios e garantir medidas a serem praticadas de forma lícita, na busca pelas melhores condições para a vida humana. Combinados com a Lei Orgânica do Município e a Lei de Uso e Ocupação do Solo, esses instrumentos se convertidos em ações eficientes, tendem a resultar em políticas urbanas satisfatórias.

Buscando expor essa questão, o presente trabalho tem como objetivo discutir o reconhecimento da qualidade ambiental urbana na legislação municipal, especificamente no Plano Diretor, analisando o caso de Araçatuba ${ }^{8}$ SP. A pretensão é, sobretudo, demonstrar o enfoque abstrato que a legislação atribui a importantes elementos de estudo das ciências ambientais. E ainda entender como tal norma interpreta a qualidade ambiental urbana.

\section{A importância da legislação municipal}

Entendendo-se a legislação como um conjunto de leis necessário para a organização de determinado espaço, pode-se reconhecer que, para organizar a cidade, é preciso estabelecer critérios pertinentes a esse objetivo. Tais critérios não devem conter procedimentos meramente instrumentais, mas acessíveis à área em questão.

A Constituição Federal do Brasil de 1988, em seu artigo 182, traz a obrigatoriedade do Plano Diretor para as cidades com mais de 20.000 habitantes, reforçada com a regulamentação da Lei no 10.257/2001, conhecida como Estatuto da Cidade.

Essa medida consistiu em mais uma iniciativa de ordenar o espaço municipal, com a intenção de disciplinar algumas normas urbanísticas, tendo

\footnotetext{
${ }^{8}$ Araçatuba localiza-se na região noroeste paulista, a aproximadamente $530 \mathrm{~km}$ da capital.
} 
em vista a expansão. "O Plano Diretor passou a ser uma referência, mas mesmo assim, o fato de ser constituído por diretrizes que necessitam de outros instrumentos legais para sua concretização, leis de uso e ocupação do solo, por exemplo, deixa um espaço para desvios." (NEGREIROS; SANTOS, 2001, p. 142).

Segundo Mendonça (2001, p. 151), antes da Constituição Federal de 1988, os referidos planos não tinham as características adquiridas atualmente e objetivavam constituir documento para a solicitação de recursos e implantar programas setoriais nos municípios, visando, portanto, a investimentos. Representavam "planos de desenvolvimento" que consistiam em programas de ações dos governos municipais que poderiam ser financiados pelo Governo Federal, executados ou não.

Ainda de acordo com a autora, questões referentes à produção, ao uso e à apropriação do espaço urbano não constavam necessariamente nesses planos municipais, podendo compor outras legislações. O que havia eram estímulos ao maior potencial construtivo, sobretudo nas áreas mais centrais da cidade. Isso reforçava a concentração e as consequências negativas nesses locais. As atividades foram setorizadas territorialmente, impedindo, muitas vezes, a proximidade de atividades complementares e freando a multiplicidade de usos que diminuiria os deslocamentos da população. O tratamento desigual das diferentes zonas deu enfoque à desigualdade, ao invés de reconhecer a diversidade presente na cidade (MENDONÇA, 2001, p. 152-153).

Com o atual documento, "a sociedade brasileira passou a experimentar uma nova ordem econômica, política e social" (CARNEIRO, 1998, p. 15), e um dos seus corolários é a garantia do bem-estar às populações. Ficou definido que a política de desenvolvimento urbano tem como objetivo atender de forma ordenada o desenvolvimento das funções sociais da cidade, garantindo o bemestar de seus habitantes.

A lei maior provoca modificações importantes ao subordinar a propriedade urbana ao cumprimento de sua função social e define o caráter urbanístico que faltava ao Plano Diretor (MENDONÇA, 2001, p. 154). A relação entre o público e o privado sofre alterações, uma vez que o proprietário 
particular deverá seguir os ditames da lei, mediante o fato da propriedade não ser um direito absoluto, e o Poder Público tende a mudar as estratégias que incidem sobre a construção das formas urbanas.

Porém a gestão não progrediu em todos os municípios na mesma totalidade em que a lei foi estabelecida, concedendo autonomia para a sua elaboração. Essa eficácia reduzida refere-se às dificuldades em dar aplicabilidade aos preceitos legais, suprindo a necessidade técnica e participativa do interesse coletivo.

Em seus estudos, Braga (1995) abordou três questões referentes ao Plano Diretor, sendo que, na primeira, se atentou ao fato de os gestores incorporarem apenas a impressão burocrática do plano, não se conscientizando do potencial do planejamento nele existente. A segunda questão enfatizou que grande parte dos planos diretores é elaborada por órgãos ou empresas que não compõem o quadro da administração pública local, adequando o documento às particularidades técnicas, todavia 0 inviabilizando em termos políticos até mesmo por desconhecimento dos problemas da área.

A terceira questão referiu-se à democratização em sua elaboração, destacando-se a obrigatoriedade de participação das entidades representativas da sociedade no processo de planejamento municipal. O autor desenvolveu suas hipóteses, chamando a atenção para o dever da própria municipalidade em elaborar o plano, e que as características peculiares do município devem ser consideradas, ressaltando a ideia de que o "plano diretor deve ser do tamanho do município, nem maior, nem menor." (BRAGA, 1995, p. 09).

Porém, deve-se fazer uma interpretação restritiva quanto a esta última ideia da dimensão do plano, tendo em vista, eventuais situações que, Monteiro (2000, p. 90) assim expressa:

Chamo a atenção também para que se considere adequadamente, na análise do sistema, elementos ou variáveis que, por sua própria natureza não estão implicitamente amarradas à ocorrência espacial do sistema mas, ao contrário, transcendem a ela [...]. 
O autor se refere ao clima, aos fenômenos hidrológicos fluviais e superficiais que podem ultrapassar os limites do sistema. Considerando a grandeza espacial do sistema urbano, todos os instrumentos aptos ao seu gerenciamento, devem se estender na medida em que for necessário abranger os limites externos dos seus elementos. Acredita-se que Braga (1995, p. 09) refere-se, portanto, ao Plano Diretor que é insuficiente no conteúdo (deveria abranger a área total) ou que é exagerado (abrange mais do que deveria), sendo em ambos os casos, um documento que não se enquadra na realidade da área.

Com relação ao Estatuto da Cidade, este dispõe sobre as diretrizes gerais da política urbana, enfocando seus instrumentos e as finalidades do Plano Diretor. No parágrafo único do artigo $1^{\circ}$ da lei em questão, o equilíbrio ambiental é referido como uma necessidade coletiva que deve ser regulada. $O$ artigo $2^{\circ}$, seus incisos e alíneas trazem um rol de garantias e aspectos que devem ser objetivados pela política urbana, muitos destes relacionados à qualidade ambiental.

Percebe-se que não faltam dispositivos que fazem menção indireta e até mesmo direta à qualidade ambiental urbana. Entretanto, é necessário promover mais iniciativas para a prática e o conhecimento da população sobre a temática, frequentemente interpretada apenas como saneamento básico.

Essa aproximação com o abastecimento de água, esgotamento sanitário, limpeza urbana e coleta de lixo, e drenagem urbana ${ }^{9}$ pode ter origem no fato de que o Poder Público, através da execução das políticas urbanas, evidencia que tais infraestruturas da cidade são o aspecto determinante da qualidade ambiental. Como dito anteriormente, há uma grande diversidade de indicadores mensuráveis, o que resulta em avaliações que possuem propostas também distintas.

Assim, Buccheri Filho (2006, p. 06) aponta a divergência das definições de qualidade ambiental que incide sobre duas orientações: os que a associam aos aspectos socioeconômicos e os que ressaltam mais as condições do

\footnotetext{
${ }^{9}$ Indicadores frequentemente utilizados nas pesquisas do IBGE referentes ao saneamento básico.
} 
ambiente natural. A combinação de ambas não seria a solução para pacificar tais confrontos:

\begin{abstract}
Quando se associa aspectos socioeconômicos com aspectos ambientais, pode ocorrer uma avaliação inadequada da qualidade, pois, uma localidade pode apresentar, por exemplo, uma boa infraestrutura como rede de telefonia, água, energia elétrica, tv a cabo, escola, etc., mas não apresentar, por exemplo, arborização e áreas verdes. Isto quer dizer que segundo os aspectos socioeconômicos a qualidade seria boa, porém, segundo aspectos do meio físico a qualidade seria ruim. Esta confusão acontece porque o conceito de "ambiente" passou por modificações ao longo do tempo. Antes da grande popularização das questões ambientais, ocorrida após a década de 1970, a palavra "ambiente" relacionava-se mais aos aspectos do meio físico.
\end{abstract}

Entende-se que as pessoas possuem mais familiaridade com as discussões que envolvem os problemas da habitação, embora a questão ambiental seja intensamente divulgada hoje, mas ainda carente de práticas individuais de conscientização. Isso pode decorrer de uma percepção escalar equivocada, que atribui a solução a iniciativas globais e não locais ou individuais.

O trabalho de Borja (1998) sob um enfoque diferente, também conseguiu demonstrar a falta de uniformidade quanto ao desenvolvimento de um conceito e, a maior influência da infraestrutura urbana básica sobre os habitantes de determinada área.

A autora propôs uma metodologia de qualidade ambiental em nível local, aplicando três questionários, sendo que o primeiro e o que será destacado foi um questionário aberto para saber quais os indicadores mais relevantes para a avaliação dessa temática. De um total de 129 pessoas que receberam o questionário, apenas 51 efetivaram sua participação. Compuseram esse grupo, a princípio, pesquisadores de diversas áreas do conhecimento, representantes do poder público e da sociedade civil tanto do estado da Bahia, quanto na escala nacional.

As respostas que mais ocorreram foram listadas e classificadas em atributos naturais da paisagem urbana, infraestrutura e serviços que a cidade deve oferecer à população. O saneamento básico foi o aspecto que recebeu 0 maior número de indicações, sendo citados, sucessivamente, a coleta, o 
tratamento e o destino final dos resíduos sólidos, o abastecimento de água com qualidade e quantidade, e o esgotamento sanitário.

A arborização foi o $25^{\circ}$ elemento mais citado. Em contrapartida, das 41 variáveis consideradas, o clima urbano ficou em último lugar em número de referências, o que sugere a propagação ainda insuficiente desse elemento, cuja incidência negativa também resulta em muito desconforto.

Tudo leva a crer que o indicador clima urbano, pelos estudos já propagados na literatura nacional, necessita que seus elementos geradores sejam mais realçados. Para isso, a legislação deveria contemplar a questão dos usos poluidores, da impermeabilização do solo e da insuficiência de vegetação, por exemplo, instigando o leitor à compreensão de que, individualizados, podem causar efeitos prejudiciais ao conforto da população e, em conjunto, podem gerar ilhas de calor urbanas.

Inobservâncias à parte, a lei de uso e ocupação do solo e o zoneamento ambiental são citados cumulativamente com o Plano Diretor como instrumentos dentro do planejamento municipal para viabilizar a política urbana. Na primeira, há um capítulo referente ao Plano Diretor que é indicativo da preocupação em assegurar, entre outras necessidades, qualidade de vida à população. A definição do documento como "instrumento básico da política de desenvolvimento e expansão urbana" é complementada com as seguintes informações. (Quadro 1).

Nesse quadro, destaca-se a necessidade de revisão dos planos diretores em um intervalo decenal, considerando que, durante esse período, podem ocorrer muitas mudanças no interior dos municípios. São Paulo e Porto Alegre, entre outros municípios, são exemplos de localidades que já tiveram essa norma revista. Segundo o Instituto Brasileiro de Geografia e Estatística (IBGE, 2010), existem, hoje, 1.934 municípios com mais de 20.000 habitantes, emergindo a dúvida se realmente todos esses documentos estão sendo revistos. 
Quadro 1 - Algumas características do Plano Diretor, segundo o Estatuto da Cidade

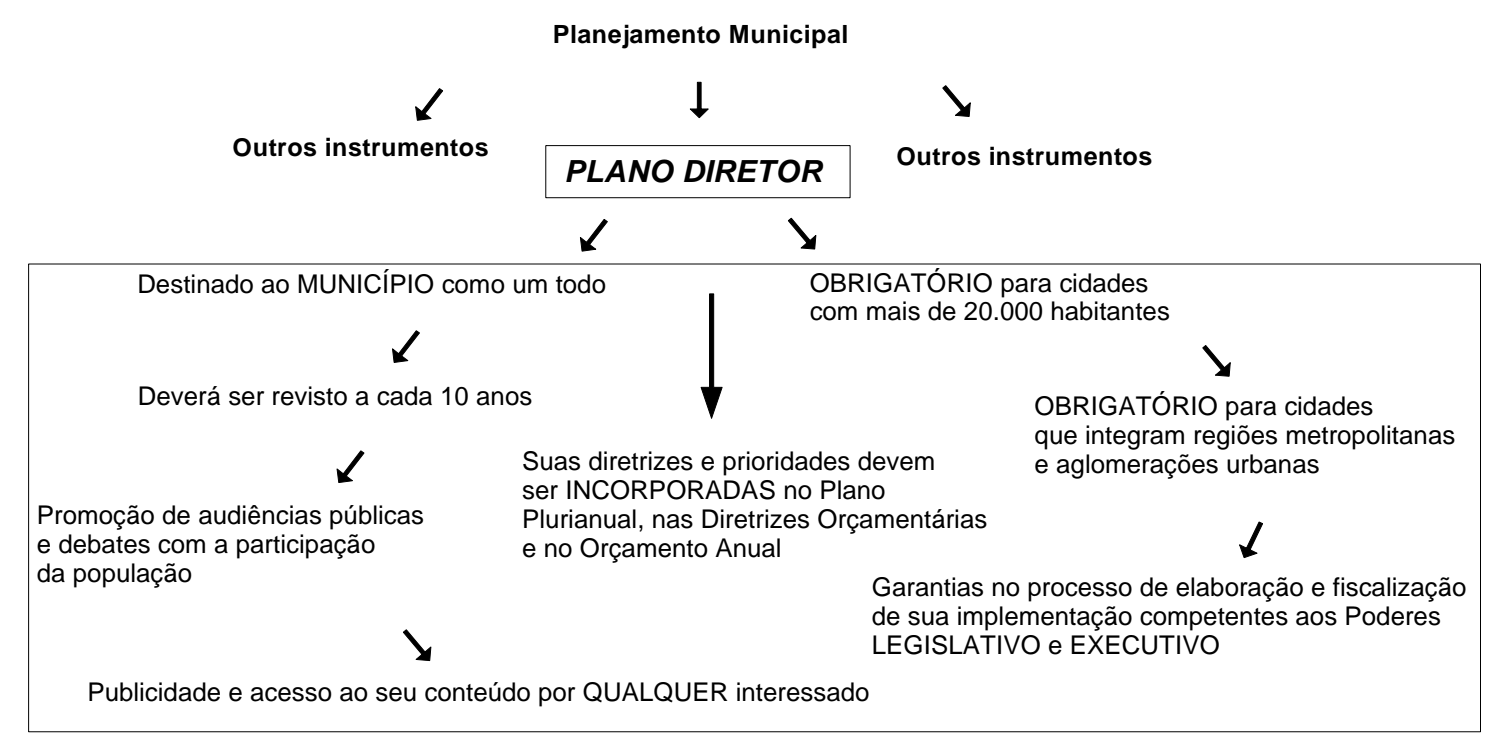

Organização: Minaki, 2011.

Com relação ao Estatuto, quando este se refere às "cidades sustentáveis" (artigo $2^{\circ}$, inciso I), a questão primária é sobre o conceito atribuído a essa expressão, já que seu uso passou a ser um hábito em discursos políticos. Embora a legislação não tenha a preocupação em conceituar, e sim impor normas, a princípio, acredita-se que a cidade sustentável apresentada consiste no modelo ideal de habitat que, indiscutivelmente, não existe e não há condições para que se torne viável. Sobre esse aspecto, Vizzoto e Prestes (2009, p. 88) interpretam a concepção dada pelo Estatuto da Cidade da seguinte maneira:

Cidades sustentáveis são cidades que garantem direitos mínimos aos seus cidadãos [...].

De outra banda, a cidade sustentável, no Estado Socioambiental Democrático de Direito, é uma cidade democrática. A garantia do direito para as futuras gerações implica a adoção dos princípios da precaução e da prevenção como elementos informadores das políticas públicas, em especial da urbano-ambiental.

Pela redação da norma, entende-se que as cidades sustentáveis não visam a garantir os direitos mínimos aos seus cidadãos, e o mínimo é a resposta esperada pelo eleitorado em relação ao poder público. O que se visualiza é a proposta de uma condição impossível de se alcançar na atual 
realidade das cidades, que não são bem representadas pelo uso dessa expressão.

Posteriormente, será tratada a questão de que muitas referências presentes na legislação possuem, de fato, um significado, ou seja, seu conceito jurídico, mas que está aquém da interpretação concebida, por exemplo, pelos geógrafos.

\section{Análise do Plano Diretor de Araçatuba-SP com ênfase à qualidade ambiental urbana}

O Plano Diretor de Araçatuba foi instituído pela Lei Complementar $n^{\circ}$ 168, de 06 de outubro de 2006. Trata-se de um documento extenso e repetitivo, com seis títulos distribuídos em 17 capítulos, totalizando 165 artigos. As referências à qualidade ambiental, implícitas ou explícitas, serão transcritas para possíveis interpretações; consequentemente, por entendê-la como um indicador de qualidade de vida, este conceito também será destacado em algumas passagens da norma.

Ressalta-se que compôs a análise os Títulos I (Dos princípios, objetivos e diretrizes gerais da política urbana), II (Do ordenamento territorial do município) e III (Das diretrizes gerais do uso do solo), por considerar que o conteúdo a ser observado tem maior incidência nessas partes do que nas demais.

Segue, portanto, a transcrição de alguns artigos do Plano Diretor, em sua forma integral ou apenas em trechos, com grifos para fins de ressalva do uso do termo ou da expressão, bem como comentários a respeito da possível interação entre a Geografia e o Direito Urbanístico.

\footnotetext{
Art. 1‥ Os agentes públicos, privados e sociais responsáveis pelas políticas e normas explicitadas neste Plano Diretor devem observar e aplicar os seguintes princípios:

$[\ldots]$

II - promover a cidade sustentável para todos, valorizando os aspectos relativos à moradia, ao saneamento ambiental, à infra-estrutura urbana, ao transporte, aos serviços públicos, ao trabalho e ao lazer para as presentes e futuras gerações;

$[\ldots]$

VIII - preservação e recuperação do meio ambiente natural;
} 
No trecho em análise, muitas palavras ou expressões são utilizadas caracterizando referências genéricas ao que é interpretado como cidade sustentável, preservação, recuperação e meio ambiente natural. Não há pretensão da norma em explicar vocábulos. Entretanto, em algumas situações, seu uso constante requer o esclarecimento do que o legislador entende por aquilo a que se refere com veemência, para também não gerar polêmica quanto ao sentido da imposição estabelecida. Porém ocorre que, muitas vezes, o que é para ser eficiente pode assemelhar-se a uma condição meramente discursiva.

Assim como muitos dispositivos ambientais presentes na atual Constituição filiam-se ao Relatório Brundtland de $1987^{10}$, nota-se que o legislador municipal buscou equiparar expressões e conceitos utilizados pelo legislador constituinte. A referência às "presentes e futuras gerações" é uma ideia originariamente embutida no conceito de desenvolvimento sustentável, que se propagou pelo documento mencionado.

Para atender o princípio da cidade sustentável (inciso l) é preciso que o desenvolvimento respeite essa sustentabilidade apregoada. Porém, chama-se a atenção para o que Salinas Chávez e Middleton (1998) ressaltam sobre a falta de consenso entre os autores sobre a cidade sustentável. Para eles, a sustentabilidade depende de sua incorporação no processo produtivo e social, da eficiência energética alcançada pela paisagem, a partir do uso de tecnologias mais apropriadas.

$\mathrm{O}$ inciso não possibilita esse entendimento mais abrangente e, o artigo não faz referência explícita à qualidade ambiental urbana dentro do rol dos princípios que devem estar contidos no Plano Diretor.

Art. 2․ A propriedade cumpre sua função social quando atende, simultaneamente, aos seguintes requisitos:

I - o atendimento das necessidades dos cidadãos quanto à qualidade de vida, à justiça social, ao acesso universal aos direitos sociais e ao desenvolvimento econômico;

\footnotetext{
${ }^{10}$ Relatório também conhecido como Nosso Futuro Comum, elaborado pela Comissão Mundial sobre Meio Ambiente e Desenvolvimento criada pela Organização das Nações Unidas (ONU). Para mais informações, consultar a obra: COUTINHO, Ronaldo do Livramento. Direito ambiental das cidades: questões teórico-metodológicas. In: COUTINHO, Ronaldo; ROCCO, Rogério (Org.). 0 direito ambiental das cidades. Rio de Janeiro: Editora Lumen Juris, 2009. p. 01-49.
} 
II - a compatibilidade do uso da propriedade com a infra-estrutura, equipamentos e serviços públicos disponíveis;

III - a compatibilidade do uso da propriedade com a preservação da qualidade do meio ambiente urbano e natural;

De acordo com o artigo acima, compõe a função social da propriedade o atendimento às necessidades dos cidadãos quanto à qualidade de vida. Tratando-se de um conceito amplo, torna-se difícil entender qual o parâmetro utilizado para averiguar se está sendo cumprida tal função social com base nesse indicador.

A função social da propriedade, segundo o artigo, é cumprida quando há compatibilidade do uso com a infraestrutura, serviços públicos e equipamentos disponíveis. E que esse uso mantenha a preservação da qualidade do meio ambiente urbano e natural. Todavia, sabe-se que não só no caso específico de Araçatuba, mas, de forma geral, as prefeituras têm autorizado o aproveitamento das testadas dos lotes para a instalação de comércio ou serviços, ao regulamentarem tais ações na lei de uso e ocupação do solo. Com a autorização, muitos impactos podem ser gerados, e a fiscalização, na maioria das vezes, é insuficiente. Hough (1998, p. 20-21), em abordagem sobre a remodelação das cidades com base na ecologia urbana, acredita que a economia do meio deveria seguir o princípio do mínimo esforço. Trata-se da ideia de que com um mínimo de energia é possível obter um máximo de benefícios ambientais, econômicos e sociais. Nos países em desenvolvimento, o processo de reciclagem demonstra o princípio da economia dos meios, pois "reduce la cantidad de basura que se acumula en los vertedoros, proporciona un medio de vida a un setor de la población, y el processo proporciona beneficios medioambientales, sociales, y de ahorro energético." (HOUGH, 1998, p. 21).

E assim, este autor traz vários exemplos de mitigação de impactos ambientais ilustrados com projetos já realizados em diferentes áreas, para serem aplicados na cidade moderna. Com relação à água, por exemplo, considera que as ruas podem servir como armazenadoras temporárias das águas pluviais, fazendo o mesmo que os coletores instalados nas casas. São formas de reconectar a água urbana com o ciclo hidrológico, podendo ser 
aproveitada, posteriormente, para regar jardins e lavar carros $(\mathrm{HOUGH}, 1998$, p. 79).

São várias formas de obter vantagem sobre o que comumente representa um problema à cidade. Ao referir-se sobre o cumprimento da função social pela propriedade, o legislador é genérico, pois inúmeras práticas precisam ser efetivadas, a começar por cada indivíduo-proprietário para se alcançar o estado de equilíbrio socioambiental a que sempre a lei evidencia.

Dessa forma, a propriedade urbana pensando nas condições ambientais, só cumprirá sua função social se existir uma cidade mais comprometida com os seus elementos naturais.

Ressalta-se ainda que, entre as diferentes interpretações sobre o que é qualidade de vida e, consequentemente, qualidade ambiental, a remuneração quase sempre é associada aos termos, podendo-se constatar que obtê-las está muito condicionado ao poder aquisitivo das pessoas.

Nesse sentido, Martinelli (2004) elabora um índice de qualidade ambiental urbana, a partir de indicadores disponíveis em institutos de pesquisas, mesmo considerando as limitações com o trabalho de indicadores estatísticos. A autora busca destacar a estreita relação entre a questão da segurança, da qualidade de vida e ambiental com a baixa qualidade ambiental e altos percentuais de violência nas cidades brasileiras, especialmente as de porte médio (MARTINELLI, 2004, p. 85). Uma de suas conclusões é que a desigualdade social reflete na desigualdade da oferta da melhor infraestrutura.

Morato, Kawakubo e Luchiari (2005) utilizaram cinco índices (abastecimento de água, esgotamento sanitário, coleta de lixo, vegetação e domicílios improvisados) na avaliação da subprefeitura de Campo Limpo, no município de São Paulo, sob a perspectiva da justiça ambiental. Os autores fizeram uma comparação entre a magnitude dos problemas ambientais e identificaram os grupos populacionais mais vulneráveis. Concluíram que o rendimento dos responsáveis pelos domicílios teve grande correlação espacial com a qualidade ambiental urbana e mais especificamente, com a distribuição da vegetação. 
No caminho inverso, o presente documento em análise trata essa condição como se fosse algo intrínseco à cidade ou espontâneo na vida dos munícipes. É de ciência de todos que a condição de cidade sustentável é um estágio bastante idealista dentro de um plano que deve propor diretrizes para a formação de uma política urbana eficiente. Sabe-se que, em muitas cidades, são criados loteamentos ocupados antes mesmo de ofertarem a infraestrutura básica aos cidadãos. Em outras palavras, não se respeita esse princípio, e há inúmeros precedentes que não justificam essa menção, tornando o documento incoerente nesse aspecto.

Art. 3‥ Para garantir o cumprimento das funções sociais da cidade, o Poder Público Municipal deverá atuar de maneira a:

$[\ldots]$

III - aumentar a oferta de moradias sociais, evitando a degradação de áreas de interesse ambiental pela urbanização;

$[\ldots]$

V - promover usos compatíveis com a preservação ambiental;

O inciso III do artigo em destaque é comumente desrespeitado, ocorrendo descobertas de situações irregulares, denunciadas pela própria população. Atenuar a degradação dos espaços deveria ser uma medida amplamente difundida, aumentando a responsabilidade do Poder Público Municipal perante a busca por uma condição ambiental mais apropriada à vida humana.

Em contrapartida, há também a dificuldade em exercer esse tipo de controle. Mas a dificuldade é agravada em núcleos de ocupação maiores e com crescimento populacional significativo, o que não é o caso de Araçatuba. Além de se enquadrar como uma cidade de porte médio, com 181.579 habitantes (Censo Demográfico do IBGE, 2010), apresenta queda no ritmo do crescimento demográfico anual desde $2000^{11}$.

Entretanto, para atender a necessidade de aumento da oferta de moradias sociais, uma possível estratégia para o adensamento, seria a

\footnotetext{
${ }^{11}$ Disponível em: <http://www.ibge.gov.br>.
} 
construção de edifícios com até 4 pavimentos. Este é o limite em que o ganho de espaço livre ainda é considerável (NUCCI, 2008, p. 42).

$\mathrm{O}$ inciso $\mathrm{V}$, por sua vez, denota a preocupação em preservar o ambiente a partir de usos compatíveis. A incorporação do ato de reduzir os impactos causados nas áreas que necessitam de cuidados especiais quando essa compatibilidade não existir, é uma necessidade. Considerando o tempo de existência de muitas cidades brasileiras, mesmo no caso de Araçatuba, com pouco mais de 100 anos, o traçado espontâneo resultante do crescimento anterior ao planejamento não condiz com tal regra, necessitando de maior zelo em relação a esse aspecto.

Art. 5․ São objetivos da política urbana:

$[\ldots]$

II - bem-estar e a melhoria da qualidade de vida dos munícipes;

III - proteção, valorização e uso adequado do meio ambiente natural e construído e da paisagem urbana e rural;

Quanto aos objetivos da política urbana, ao referir-se à qualidade de vida dos munícipes, são ressaltados os mais dependentes da condição social da família do que propriamente da gestão urbana.

$\mathrm{O}$ inciso $\mathrm{V}$ faz uma referência à qualidade ambiental, estabelecendo deveres à gestão pública. Considera-se que o nível educacional e econômico ainda influencia nos cuidados ou na ausência deles na relação que cada um mantém com o ambiente. O quanto cada indivíduo conhece e compreende sobre o assunto pode ser melhorado com as campanhas de conscientização ambiental, que, isoladamente, não são suficientes. É preciso uma base escolar e também familiar incorporada. Em outras palavras, o Estado e a família devem atuar em conjunto na perspectiva de um tratamento educacional.

Outra importante referência é a existência da qualidade ambiental rural, cujos estudos ainda são pouco difundidos, mas que podem trazer parâmetros comparativos com a qualidade ambiental urbana.

Sobre a diferenciação entre o ambiente natural e o construído, destacam-se as palavras de Alva (1997, p. 67), para quem o ambiente construído "principalmente as cidades, é o 'ambiente natural' para uma parte cada vez maior dos habitantes do planeta". 
Art. 6‥ Os objetivos que devem direcionar as formas de vivência e uso do território municipal pelos agentes públicos e privados e pelos cidadãos em geral, no estabelecimento de uma política fundiária, são os seguintes:

I - demarcar, preservar e ampliar as áreas verdes e de preservação ambiental;

O inciso I do artigo $6^{\circ}$ faz uma referência bastante positiva a respeito da ampliação das áreas verdes. Contudo essa ampliação não deve resultar apenas na transformação jurídica de lotes vazios em áreas chamadas de praças ou parques públicos e dessa forma continuarem ao longo do mandato dos gestores. É preciso verificar se as funções ecológicas, social e estética das áreas verdes ${ }^{12}$ estão sendo exercidas, em busca da qualidade ambiental e da qualidade de vida para a população.

Em trabalho sobre as praças públicas, Minaki (2007) conclui que muitas praças e áreas verdes surgiram sem um planejamento adequado em Araçatuba e, no caso das primeiras, acabam sendo usadas como local de passagem, perdendo a sua função original de proporcionar lazer para a população. "Em segundo lugar, verificou-se o descaso público quanto à implantação e manutenção de tais espaços públicos." (MINAKI, 2007, p. 186).

Outra questão desencadeada no estudo mencionado é a propensão à falta de uniformização dos equipamentos urbanos, que tendem a ser melhores e mais refinados nas áreas centrais, e escassos e inferiores nas áreas mais afastadas. De fato, não há recursos financeiros suficientes para uma distribuição igualitária dessa infraestrutura, resultando em uma hierarquia que considera aquelas em que há mais uso e que se localizam em pontos mais nobres ou que são voltadas aos interesses especulativos presentes na cidade.

Verificar a necessidade de implantar mais áreas vegetadas deve ocorrer não só no âmbito da política fundiária, mas da legislação urbanística, de forma geral, podendo-se até mesmo criar um código de arborização.

\footnotetext{
12 Em síntese, áreas verdes para Cavalheiro et al. (1999) são “(...) um tipo especial de espaços livres onde o elemento fundamental da composição é a vegetação". Buccheri Filho (2010) criou outro termo para defini-las: "espaços de uso público, livres de edificação e com vegetação", ou simplesmente, "EUPLEV", que corresponde à sigla dessa nomenclatura.
} 
Art. 7‥ Na promoção da política urbana, o Município deve observar e aplicar as diretrizes gerais estabelecidas no art. $2^{\circ}$ da Lei Federal ํㅜ 10.257, de 10 de julho de 2001, e as seguintes diretrizes locais:

$[\ldots]$

IX - preservar e recuperar o meio ambiente natural e construído, o patrimônio cultural, histórico, artístico e paisagístico;

O artigo $7^{\circ}$ faz nova referência à manutenção da preservação e à recuperação do meio ambiente natural, construído e paisagístico, mas sem dispor sobre as formas que isso pode se dar, corroborando com as ideias de Vizzoto e Prestes (2009, p. 25-26) ao considerarem que

[...] a legislação ambiental das cidades sempre se limitou a positivar normas proibitivas ou liberatórias de construções, realização de atividades ou de implantação de empreendimentos, construir. Há uma carência de política ambiental propositiva que considere as necessidades da cidade como um todo, na forma identificada na Agenda 21.

Em outras palavras, deve-se promover a política urbana a partir de iniciativas, e não apenas explicitá-la para fins de estrito cumprimento legal. Mas o que se observa é uma grande repetição, como a do princípio presente no artigo $1^{\circ}$, inciso VIII e que reaparece no inciso IX deste artigo $7^{\circ}$.

Art. 11. Calcadas nos princípios do desenvolvimento econômico e da sustentabilidade ambiental, as estratégias municipais de Araçatuba visam a:

I - promover o desenvolvimento sustentável, com a distribuição das riquezas e tecnologias;

II - possibilitar o uso e a ocupação do solo urbano em compatibilidade com o meio ambiente, o sistema viário, a infra-estrutura e as funções sociais da cidade;

$[\ldots]$

IV - promover programas de conscientização e educação ambiental;

V - articular as políticas de gestão e proteção ambiental, especificamente no que tange ao licenciamento, monitoramento e fiscalização das atividades e empreendimentos potencialmente poluidores e impactantes;

VI - preservar os recursos hídricos;

VII - universalizar o provimento dos serviços de abastecimento de água, esgoto sanitário, resíduos sólidos e drenagem urbana, na busca do pleno atendimento à população do Município.

A referência à sustentabilidade ambiental também ocorre no artigo 11, como se seus princípios fossem subentendidos por todos. O dispositivo traz ainda as estratégias visadas pelo Município, considerando uma proporcionalidade não razoável entre o desenvolvimento econômico e a questão ambiental. 
O primeiro inciso, além de relativizar os princípios do desenvolvimento sustentável, aborda a distribuição de riquezas e tecnologias. Aqui, chama-se a atenção para o fato de que nenhum gestor distribui riquezas, pois o que está ao seu alcance é potencializar a igualdade, combatendo a impunidade e as políticas que privilegiam somente determinadas classes. As dificuldades para conseguir essa meta, por todos os problemas estruturais e morais que caracterizam a política pública no país, impossibilitam qualquer outra ação de nivelamento social.

"Preservar os recursos hídricos" (inciso VI) é uma ação que reaparece no decorrer do documento, principalmente, no que se diz respeito à proteção dos mananciais, sendo fundamental incluí-los no rol de elementos cuja poluição pode dar causa à queda da qualidade do ambiente.

No que diz respeitos aos recursos hídricos, um dos problemas antigos que incide em toda época chuvosa é a inundação em áreas de grande movimento de veículos e de alta densidade de construções. A drenagem urbana insuficiente é um problema local cuja superação ou redução ainda não se efetivou.

Medidas alternativas que prescindem de propagação foram citadas por Valaski (2008, p. 62-63), tais como, os sistemas simplificados de captação de águas pluviais nas residências ou nos espaços livres. Outra, um pouco mais custosa, porém, relevante, é uma edificação ecológica com instalação hidráulica para armazenar a água da chuva e reintroduzi-la no ciclo da casa.

Tucci (1997), por sua vez, ressalta a importância de um Plano de Drenagem Urbana como parte do Plano Diretor Municipal. "No Plano Diretor de Drenagem é dado ênfase no controle através de medidas não-estruturais como o zoneamento de áreas de inundação." (TUCCI, 1997, p. 08). São vários os princípios de controle de enchentes indicados, tais como estabelecer o controle da bacia hidrográfica urbana e não de pontos isolados; contemplar em todas as análises a possibilidade de um futuro desenvolvimento da bacia; buscar evitar que a ampliação da enchente devido à urbanização seja transferida para a jusante, entre outros (TUCCI, 1997, p. 09). 
Art. 13. O macrozoneamento e o zoneamento do Município deverão atender às seguintes diretrizes:

$[\ldots]$

V - preservar, proteger e recuperar o meio ambiente natural e construído;

$[\ldots]$

VII - exigir, para o licenciamento de atividades modificadoras do meio ambiente, a elaboração prévia de Estudo de Impacto Ambiental - EIA e do respectivo Relatório de Impacto Ambiental - RIMA, bem como sua aprovação pelos órgãos competentes do Poder Público, observada a legislação específica;

VIII - exigir Estudo de Impacto de Vizinhança, e suas ações complementares, para regularização ou licenciamento das atividades ou empreendimentos potencialmente incômodos ou impactantes instalados no território do Município de Araçatuba;

Ao destacar o macrozoneamento e o zoneamento de Araçatuba, novamente ocorre o uso dos verbos preservar, proteger e recuperar o meio ambiente natural e construído. A obrigatoriedade do EIA/RIMA e a exigência do Estudo de Impacto de Vizinhança é um aspecto positivo para se prevenir o exercício de atividades que causem grandes danos ao ambiente.

Paula (2007, p. 21) sintetiza o entendimento sobre a Lei Zoneamento de Uso e Ocupação do Solo ao dizer que esta "(...) classifica os usos do solo", buscando, portanto evitar que não haja problemas futuros decorrente de um desordenamento atual.

Logo, entende-se que as atividades do (macro)zoneamento quando efetivadas, beneficiam a qualidade ambiental, pois inclui-se instrumentos de políticas urbanas que controlam a construção e a ocupação dos lotes. Paula (2007, p. 21-23) cita alguns desses instrumentos. Pode-se aplicar ao caso concreto do estudo em análise, o parcelamento, edificação ou utilização compulsória do solo, a urbanização consorciada e o Estudo de Impacto de Vizinhança.

\section{Art. 14. A ordenação e o controle do uso do solo devem evitar:}

$[\ldots]$

II - a proximidade de usos incompatíveis ou inconvenientes, especialmente junto aos usos residenciais;

III - o adensamento inadequado à infra-estrutura urbana e aos equipamentos urbanos e comunitários existentes ou previstos;

$[\ldots]$

V - a deterioração de áreas urbanizadas e não urbanizadas;

$[\ldots]$

VII - a ocorrência de desastres naturais. 
Segundo o artigo 14, a ordenação e o controle do uso do solo deve evitar a incompatibilidade, tendo como parâmetro, especialmente aquele destinado à finalidade residencial. Mas é comum verificar-se a incompatibilidade, mesmo nas áreas com esse uso, legalmente mais protegido, confrontando com a disposição normativa. A origem do problema pode estar, em alguns casos, no planejamento que "(...) é baseado somente em medidas de ordem tecnológica, sem se dar importância ao ordenamento do ambiente" ( $\mathrm{NUCCl}, 2008$, p. 03), causando prejuízos à qualidade ambiental.

Por isso, estudos sobre o potencial poluidor devem ser incorporados, invocando indicadores abrangentes que possam incluir os efeitos da poluição na saúde do ser humano e da própria vegetação. A importância da elaboração do mapa de uso do solo é primordial para a atividade do planejador urbano. Ao reconhecer a existência dessa incompatibilidade, bem como as suas agravantes, medidas devem ser tomadas.

Rocha e Figueiró (2012) utilizaram uma metodologia de baixo custo para verificar a concentração de material particulado nas principais ruas e avenidas de um bairro de Santa Maria/RS. A mensuração do material particulado, foi feita a partir da elaboração de equipamentos artesanais. Tratase de plaquetas de ferro e a colocação de fita adesiva dupla-face para a deposição de material particulado. Nesta experiência, a coleta é feita em alguns episódios, e a diferença de peso entre a plaqueta que não foi exposta ao ar livre e a plaqueta utilizada no trabalho de campo, serve como indicador das áreas com maior concentração do material particulado. Mapear o fluxo de ônibus identificando e quantificando as principais rotas que passavam pela área, também compôs seu meio de avaliação.

Os autores ainda sugeriram propostas para a redução da emissão de partículas de poluição, tais como: a conscientização e a fiscalização dos motoristas para efetuarem a regulagem do motor e a criação de barreiras de vegetação próximas às paradas de ônibus, na tentativa de minimizar o contato desses particulados com as pessoas. A criação dessas barreiras verdes também seria viável nas proximidades dos usos potencialmente poluentes. 
Evitar os desastres naturais (inciso VII) não pode ser compreendido como uma medida de planejamento, caracterizando-se mais como uma ação idealizadora, uma vez que é impossível evitar eventos naturais, sendo o mais correto expressar a tentativa de diminuir o potencial dos desastres naturais via monitoramento. O monitoramento para Lang e Blaschke (2009), significa registrar mudanças, que ocorre por meio de uma avaliação contínua. Essa prática em áreas de risco pode resultar na diminuição das perdas humanas e materiais, ou até mesmo afastar tais hipóteses.

Ainda entre os incisos, há a preocupação de "evitar a deterioração de áreas urbanizadas e não urbanizadas" (inciso V). O núcleo da questão deveria incidir sobre o verbo reduzir, tamanha a dificuldade que é sensibilizar a todos sobre os problemas ambientais urbanos e ao mesmo tempo, cumprir as medidas normativas.

Art. 15. O macrozoneamento divide o território do Município de Araçatuba considerando: [...] III - as características do meio ambiente natural e construído;

O macrozoneamento possui normas fundamentais de ordenação do território municipal, que atende aos princípios constitucionais da política urbana da função social da cidade e da propriedade urbana (artigo 16). E, segundo o artigo transcrito, divide Araçatuba respeitando suas características naturais e de seu ambiente construído.

Sabe-se, porém, que as cidades constituem o principal habitat humano e que, para se consolidarem, não houve respeito às condições naturais, porque se trata de um meio artificializado, construído sobre um meio natural. Logo, é importante que o macrozoneamento respeite as características do meio natural ainda não deteriorado, e considere as modificações dos processos naturais pela composição e relações que ocorrem na cidade, resguardando a população dos seus efeitos mais danosos.

Art. 18. O macrozoneamento tem como objetivo o ordenamento territorial do Município, de forma a permitir:

$[\ldots]$

III - a contenção da expansão da área urbana que acarrete degradação sócio-ambiental; 
Todas as referências ao macrozoneamento são ideais para qualquer cidade. E, muitas vezes, são meramente discursivas, já que a especulação financeira tem grande domínio sobre o que é efetivamente praticado no zoneamento urbano.

No inciso III, nota-se mais uma referência que articula a questão social à questão ambiental, as quais, de fato, mantêm seus vínculos.

No que tange à qualidade ambiental, não é possível limitar sua análise ao macrozoneamento, porque seu conceito não é uma característica elementar dessa política urbana. Da mesma forma, não é possível se limitar à sua definição legalista, que até 0 momento, mostrou-se insuficiente para a complexidade com que a temática é tratada pelos profissionais da área ambiental.

Art. 25. A Zona de Ocupação Induzida - Zona 1 tem como diretrizes: $[\ldots]$

VIII - promover o controle da permeabilidade do solo;

Para entender esse artigo e seu respectivo inciso, ressalta-se que estão inseridos no capítulo referente à Macrozona de Qualificação Urbana, subdividida em Zona de Ocupação Induzida, Zona de Ocupação Condicionada e Zona de Ocupação Controlada Urbana. Trata-se das áreas favoráveis ao adensamento urbano e que definem o perímetro urbano do município. Além disso, compõem o âmbito do Plano Diretor, que inclui também o bairro Engenheiro Taveira e núcleos urbanos em áreas rurais.

A Zona de Ocupação Induzida (ZOI), especificamente, é a área do território municipal com a melhor infraestrutura, índices elevados de renda social e zona de ocupação prioritária, segundo a legislação atual, havendo várias diretrizes para o seu adensamento (ARAÇATUBA, 2011, p. 37).

Com relação ao inciso VIII, considerando que a máxima vazão de uma bacia urbana é aumentada com a impermeabilização das áreas e a canalização do escoamento (TUCCI, 2003, p. 36), acredita-se que esse controle da permeabilidade é um estímulo à maior infiltração da água nas áreas dentro da ZOI que ainda possuem terrenos não edificados, subutilizados ou não utilizados. 
Nucci (2008, p. 18), ao referir-se a cidade de São Paulo, faz uma constatação que pode se estender a muitos outros locais, que é o fato de que a cidade utiliza o seu solo em uma fronteira entre o ambiente e a sociedade. A qualidade ambiental, através de outros indicadores como a vegetação, pode melhorar a questão da permeabilidade do solo e atenuar as consequências dessa fronteira tão visível.

Art. 28. A Zona de Ocupação Condicionada - Zona 2 tem como diretrizes:

I - recuperação urbana, social e ambiental;

II - promover as medidas necessárias para assegurar as condições urbanísticas e ambientais adequadas, visando a equacionar os conflitos de uso e ocupação do solo;

$[\ldots]$

VIII - adequar o sistema de drenagem;

A Zona de Ocupação Condicionada é composta por loteamentos adjacentes à área central, excluindo-se o quadrante oeste. Além dos conjuntos habitacionais e algumas chácaras, incluem-se, nessa área, o Cemitério Jardim da Luz, o Aeroporto Dário Guarita e alguns condomínios residenciais.

Tal zona consiste em uma área mais fragmentada, que reúne ainda algumas das Áreas de Especial Interesse Social. Nela, há predominância do uso misto e a carência de infraestrutura básica, principalmente em termos de drenagem urbana.

Retoma-se aqui a importância de se avaliar a qualidade ambiental de forma contínua, pois num exemplo como esse, há uma ocupação restrita porque há riscos. Da mesma forma, como destaca Monteiro (2000), há possibilidades do poder público promover estudos em diferentes escalas, sendo possível reconhecer e distinguir a potencialidade de cada unidade paisagística ${ }^{13}$.

Art. 61. As áreas definidas como AEIS 1 são aquelas ocupadas por populações de baixa renda, abrangendo ocupações espontâneas, loteamentos irregulares ou clandestinos, carentes de infra-estrutura urbana e social, na qual se pretende a implementação de programas habitacionais, podendo contemplar:

I - reurbanização;

II - remoção com reassentamento;

III - regularização urbanística, física e fundiária;

IV - recuperação de imóveis degradados;

V - provisão de infra-estrutura, equipamentos sociais e culturais;

VI - espaços públicos qualificados, serviços e comércio de caráter local.

${ }^{13}$ A delimitação de unidades de paisagem é aqui interpretada, a partir de Monteiro (2000), como uma proposta de classificação que tende a manter o caráter holístico da paisagem. Associa-se à escala da área de estudo, facilitando a sua organização e interpretação valorativa. 
A legislação referente às Áreas Especiais de Interesse Social demonstra grande preocupação com o crescimento irregular associado à queda da qualidade ambiental. Especificamente nesse artigo, constam as ações que são citadas em muitas conclusões de trabalho como aquilo que deve ser buscado pelos municípios. Logo, se estão sendo ressaltadas pelo legislador, pode significar que quase não têm sido efetivadas na prática.

Para condicionar benefícios à relação entre a sociedade e a ocupação, Nucci $(2008$, p. 07) indica como um dos procedimentos fundamentais no planejamento, a classificação da paisagem em conjuntos compostos por subespaços afins, o que facilitaria a sua compreensão.

Art. 70. Não serão objeto de regularização em AEIS 1 ou parte delas áreas que apresentem as seguintes características, devidamente comprovadas por laudo técnico:

I - impróprias à urbanização;

II - onde o nível de poluição impeça as condições sanitárias satisfatórias, até a eliminação dos agentes poluentes;

III - risco geotécnico;

IV - que ocupe área de preservação permanente (APP).

Parágrafo único. As ocupações descritas nos incisos anteriores deverão ser objeto de um plano de urbanização específica de interesse social, em que as situações de risco sejam superadas por meio da remoção e relocação da população, que deverá ter um atendimento habitacional adequado, ou pela execução de obras necessárias para eliminar o risco.

Ainda sobre as Áreas Especiais de Interesse Social, sua ocupação é vedada quando for comprovada uma série de características que causem riscos, mediante laudo técnico. Porém o parágrafo único do artigo abre uma exceção que pode dar margem às irregularidades.

Destaca-se ainda que tais situações de risco não podem ser superadas, mas controladas de modo a minimizar os problemas que a população residente tende a enfrentar. Um exemplo é o risco geotécnico de escorregamento de terras, que está bastante relacionado à ação da gravidade e às propriedades do solo.

Mais uma vez, recorre-se à ênfase da necessidade do planejador conhecer os problemas locais e, usar da conscientização ambiental, das políticas de reassentamento das populações que ocupam áreas de risco e efetivar sanções aos que violarem as normas mesmo quando tiverem o seu conhecimento, para efetivar sua fiscalização. 
Art. 71. No caso de assentamentos já existentes até a publicação desta Lei, em áreas "non aedificandi" ao longo de corpos d'água, quando não houver a possibilidade de relocação da população residente para outra área, será admitida a regularização, desde que:

I - sejam realizadas obras para adequação do sistema de drenagem;

II - seja atestado, por meio de laudo técnico, que o assentamento e as áreas à montante e à jusante não sejam prejudicadas por inundações, alagamentos ou enchentes após a urbanização;

III - a presença do assentamento não acarrete danos ambientais.

Além do parágrafo único do artigo anterior, o artigo 71 priva de uma condição mais segura as populações que ocupam áreas de risco antes da publicação do plano.

No caso do inciso III, é intensa a desproporcionalidade com a realidade local, podendo-se citar não só a poluição por lixo ou esgoto, como também o assoreamento dos rios, causado, entre vários fatores, pelo crescimento da cidade, que contribui para a degradação dos mananciais. Além disso, a Secretaria Estadual do Meio Ambiente, em 2007, divulgou que, em Araçatuba, resta apenas $1,4 \%$ da cobertura vegetal original de Mata Atlântica. Tais informações constam do acervo eletrônico do jornal Folha da Região ${ }^{14}$, configurando-se em exemplos de que a ocupação acarreta e dificilmente excluirá esse tipo de impacto sobre a natureza.

Pereira (1999, p. 253-254), ao abordar os aspectos práticos da proteção dos recursos hídricos, destaca que rios, córregos e nascentes já não são mais encarados de forma isolada e sim como elementos constitutivos de bacias, sub-bacias e microbacias. Há a preocupação com os impactos que não se limitam a determinada área geográfica, devido à fluidez da água, que se espalha para outros ecossistemas.

Faz ainda um reconhecimento importante, ao falar sobre a atuação do Ministério Público em matéria de meio ambiente, que pode ser estendida à legislação municipal e ao seu comprometimento com a qualidade ambiental:

Muito embora, seja ele um técnico legal, para lograr êxito na atuação protetiva do meio ambiente, o órgão ministerial necessita adquirir um mínimo de conhecimento técnico sobre o assunto. Tal afirmação,

\footnotetext{
${ }^{14}$ Disponível em: <http://www.folhadaregiao.com.br>.
} 
como não poderia deixar de ser, vale também para a proteção dos recursos hídricos.

$[\ldots]$

Note-se aqui que não se pretende do órgão ministerial a obtenção de verdadeira especialização no assunto - salvo se esta for de seu interesse - mas apenas a facilitação de sua tarefa através de um mínimo de conhecimento, o qual, inclusive, Ihe proporcionará ampla vantagem sobre seus interlocutores em qualquer fase da investigação e eventual processo. (PEREIRA, 1999, p. 259).

Art. 72. As diretrizes gerais da política municipal de mobilidade urbana buscam garantir as condições necessárias ao exercício da função de circular, locomover, parar e estacionar, facilitando os deslocamentos e a circulação, com os seguintes objetivos:

$[\ldots]$

V - compatibilizar o planejamento e a gestão da mobilidade urbana, para promover a melhoria da qualidade do meio ambiente;

Esse é um aspecto bastante difícil de ser planejado, principalmente quando se considera a extensa lista de fatores que podem afetar a mobilidade urbana: a quantidade excessiva de veículos circulando; a infraestrutura viária; a ausência de exclusividade do transporte público, que só possui vias próprias em algumas capitais brasileiras; as linhas e os trajetos insuficientes para atender à população em geral; e a frequência com que essas linhas são ofertadas.

Os últimos dois aspectos estão intrinsecamente relacionados à ordem financeira da questão - com tantos setores para desenvolver, nem sempre o viário será privilegiado, considerando que a facilidade de crédito e a tendência da classe média em adquirir veículo próprio para circulação tornam a opção menos apelativa.

O inciso $V$ é dotado de uma condição também presente nos estudos de qualidade ambiental: como gerir a mobilidade urbana sem ter prejuízo nas condições ambientais da cidade. Acredita-se na relação intrínseca e não acessória da mobilidade com as questões voltadas à poluição e ao planejamento o uso do solo. Uma lei para o sistema viário pode ir mais além, tratando também de aspectos de qualidade de vida, como a segurança.

Art. 75. Em todo o território do Município de Araçatuba, será permitido o uso misto, desde que atendidas as restrições às atividades geradoras de impactos e de incômodos, expressas em cada zona definida nesta Lei.

Parágrafo único. Ficam excluídos desta condição os loteamentos estritamente residenciais e os loteamentos estritamente industriais que já estejam consolidados, nos quais o uso préestabelecido não tenha sido alterado. 
Sobre o uso do solo, essa permissão do artigo 75 é fundamental porque a realidade da ocupação das cidades é ter o predomínio de uso misto. Porém há muitos loteamentos residenciais, consolidados antes da lei, e que não cumprem o requisito especificado no caput do artigo. Isso é um problema, considerando que a norma posterior é mais rigorosa que as regras seguidas anteriormente.

Por isso, ressaltar o fato de que o plano deve ser um documento adaptável às mudanças que forem necessárias (FABRíCIO, 2007, p. 30).

\section{CONCLUSÃO}

Dos artigos analisados, apenas o inciso III do artigo $2^{\circ}$ do Plano Diretor de Araçatuba faz referência explícita à qualidade do ambiente urbano. Nos demais, não há esse reconhecimento e notou-se a possível associação da palavra "preservação" ao conceito. Geralmente, a preservação esteve acompanhada dos seguintes complementos: "preservação e recuperação do meio natural e construído", considerado um princípio dentro da legislação analisada.

Quanto à qualidade de vida, o caput dos artigos $2^{\circ}$ e $5^{\circ}$ fazem a sua referência genérica, também não citando diretamente o que é abrangido pelo conceito. Porém, percebe-se que o termo é incluído junto aos aspectos da infraestrutura, da justiça social e do acesso aos serviços públicos.

O enfoque abstrato da legislação compromete a interpretação literal das normas, sendo necessária uma interpretação que busque a finalidade do seu conteúdo. Além disso, o conteúdo repetitivo demonstra o caráter analítico do plano, que poderia ser sintético, mais propositivo e menos evasivo.

A falta de interdisciplinaridade com áreas de estudos ambientais faz 0 legislador cometer falhas ou ser impreciso. Entendimentos equivocados foram percebidos, tal como o presente no inciso VII do artigo 14, sobre "evitar a ocorrência de desastres naturais". O tratamento técnico, em situações como a destacada, deve ser incorporado. 
De forma geral, a qualidade ambiental urbana não é considerada um princípio que norteia o conteúdo normativo do documento. Não sendo possível, limitar-se apenas aos conceitos e referências jurídicas destacadas, para entender a complexidade da questão.

\section{CONSIDERAÇÕES FINAIS}

Para concluir esta análise, é importante fazer algumas considerações gerais sobre a totalidade da leitura feita dos três títulos do Plano Diretor. Neles, percebeu-se a referência constante aos três agentes significativos para a efetivação das normas, a saber: os públicos, os privados e os cidadãos, de maneira que, isoladamente, não é possível alcançar as metas préestabelecidas.

Embora, para muitos geógrafos, a expressão meio ambiente não seja a mais completa quando há referência à natureza como um todo, aqui houve a sua consideração por respeitar a opção da nomenclatura utilizada na Constituição Federal, ou seja, a lei maior de um país.

Por fim, não houve a pretensão de corrigir a redação dos artigos ou incisos, mas fazer ressalvas quanto ao distanciamento que o legislador demonstra do assunto, em determinados pontos. Do mesmo modo, não se está defendendo que o plano seja um documento técnico ambiental, e sim que haja maior aproveitamento dos estudos acadêmicos constantemente realizados e, maior esforço em não negligenciar a interpretação de palavras como "preservação", "deterioração", "conservação", "equilíbrio", entre tantas outras, quando for necessário.

Quanto à articulação entre a Geografia e o Direito Urbanístico, tem-se que aquela pode ser importante instrumento para a compreensão da temática ambiental, que necessita ser abordada de modo mais adequado à realidade nas normas do Direito Urbanístico. 


\begin{abstract}
O Direito Urbanístico dialoga diretamente com o Direito Constitucional, onde está sua matriz diretiva, com o Direito Ambiental, com o Direito Administrativo e com o Direito Civil, por exemplo. Todavia, é com ramos do conhecimento não-jurídicos, como o Urbanismo, a História, a Sociologia e a Antropologia, entre outros, que há uma vinculação mais próxima com o Direito Urbanístico. (VIZZOTTO; PRESTES, 2009, p. 14).
\end{abstract}

Apesar de as autoras não se referirem à Geografia, acredita-se que, em muitos aspectos, esta ciência pode ser pacificadora de dúvidas, competente para aquiescer confrontos de vocabulários e interpretações equivocadas que são divulgadas em legislações como aquelas utilizadas na área ambiental.

Acredita-se também que o Plano Diretor deve se fundamentar em ideais mais tangíveis, e pressupõe-se que haja um mínimo de cumprimento desses para que não se torne apenas um rol de intenções não efetivadas. A princípio, é preciso ser de fácil compreensão, porém mais específico quando se refere às práticas, cujos verbos nem mesmo são explorados no decorrer do texto, mas apenas apresentados como solução. O que é preservar, conservar, recuperar para o contexto das condições ambientais da cidade precisa ficar claro.

Não obstante a lei traga ao plano teórico alguns conceitos jurídicos, muitas vezes, estes são limitados, em face da complexidade maior de sua compreensão na realidade cotidiana das cidades. Sob essa concepção, a interdisciplinaridade é um instrumento de pesquisa que pode auxiliar e sanar problemas de correspondência entre as diferentes áreas que buscam tratar os mesmos problemas, cada qual segundo sua especificidade.

A Geografia e o Direito Urbanístico podem trocar conhecimentos e se beneficiarem com a simbiose dessa articulação. A primeira serve-se de uma busca incansável pela compreensão da realidade prática dos fenômenos sociais, econômicos e ambientais, enquanto a segunda é norteada por um rol de normas que devem ser cumpridas e interpretadas mediante situações consideradas passíveis de punição.

\title{
REFERÊNCIAS
}

ALVA, E. N. Metrópoles (in)sustentáveis. Rio de Janeiro: Relume Dumará, 1997. 
AMORIM, M. C. de C. T. Climatologia e gestão do espaço urbano. Mercator, Fortaleza, número especial, p. 71-90, dez. 2010. Disponível em: <http://www.mercator.ufc.br/index.php/mercator/article/viewArticle/534>.

Acesso em: 30 abr. 2011.

ARAÇATUBA. Departamento de Água e Esgoto. Plano Municipal de Abastecimento de Água e Esgotamento Sanitário do Município de Araçatuba. Alternativas para o sistema de abastecimento de água e esgotamento sanitário com diretrizes de ampliação e melhoria dos sistemas versão final. Relatório Técnico - RT3, abr. 2011. 158p. Disponível em: <http://www.aracatuba.sp.gov.br>. Acesso em: 20 fev. 2012.

. Lei Complementar $n^{\circ} 168$, de 06 de outubro de 2006. Institui o Plano Diretor do Município de Araçatuba. Disponível em: $<$ http://www.aracatuba.sp.gov.br>. Acesso em: 20 dez. 2010.

BORJA, P. C. Metodologia para a avaliação da qualidade ambiental urbana em nível local. In: CONGRESO INTERAMERICANO DE INGENIERÍA SANITARIA Y AMBIENTAL, 26. , 1998, Lima. Anais... Lima: AIDIS, 1998. Disponível em: $<$ http://www.bvsde.paho.org>. Acesso em: 05 mai. 2009.

BRAGA, R. Plano diretor municipal: três questões para discussão. Caderno do Departamento de Planejamento (Faculdade de Ciências e Tecnologia, UNESP), Presidente Prudente, v. 1, n. 1, p. 15-20, ago. 1995. Disponível em: <http://www.dadosmunicipais.org.br/arquivos/plano_diretor_1237397365.pdf>. Acesso em: 24 ago. 2011.

BRASIL. Constituição (1988). Constituição da República Federativa do Brasil: promulgada em 05 de outubro de 1988. Disponível em: <http://www.planalto.gov.br>. Acesso em: 20 fev. 2011.

Lei no 10.257, de 10 de julho de 2001. Regulamenta os artigos 182 e 183 da Constituição Federal, estabelece diretrizes gerais da política urbana e dá outras providências. Disponível em: <http://www.planalto.gov.br>. Acesso em: 20 fev. 2011.

BUCCHERI FILHO, A. T. O planejamento dos espaços de uso público, livres de edificação e com vegetação (EUPLEVs) no município de Curitiba, PR: planejamento sistemático ou planejamento baseado em um modelo oportunista? 2010. 226 f. Tese (Doutorado em Geografia) - Setor de Ciências da Terra, Universidade Federal do Paraná, Curitiba. Disponível em: <http://dspace.c3sl.ufpr.br/dspace/bitstream/1884/24093/1/TESE\%20Alexandre \%20Theobaldo\%20Buccheri\%20Filho.pdf>. Acesso em: 11 abr. 2012.

. Qualidade ambiental no Bairro Alto da XV, Curitiba/PR. 2006. $80 \mathrm{f}$. Dissertação (Mestrado em Geografia) - Setor de Ciências da Terra, Universidade Federal do Paraná, Curitiba. Disponível em: $<$ http://www.geografia.ufpr.br/laboratorios/labs/?pg=publicacoes-php>. Acesso em: 11 abr. 2012.

CARNEIRO, R. de J. M. Organização da cidade: planejamento municipal, plano diretor e urbanificação. São Paulo: Max Limonad, 1998. 142p. 
CAVALHEIRO, F.; NUCCI, J. C.; GUZZO, P.; ROCHA, Y. T. Proposição de terminologia para o verde urbano. Boletim Informativo da Sociedade Brasileira de Arborização Urbana, Rio de Janeiro, n. 3, 1999. Disponível em: <http://www.geografia.ufpr.br/laboratorios/labs/index.php>. Acesso em: 04 dez. 2009.

FABRICIO, E. P. Plano Diretor. In: PAULA, A. S. de. (Org.). Estatuto da cidade e o plano diretor municipal. São Paulo: Lemos e Cruz, 2007. p. 2934.

FERNANDES, E. Direito urbanístico e política no Brasil: uma introdução. In: FERNANDES, E.(Org.). Direito urbanístico e política urbana no Brasil. Belo Horizonte: Del Rey, 2001. p. 11-52.

HOUGH, M. Naturaleza y ciudad: planificacion urbana y processos ecologicos. Barcelona: Gustavo Gilli, 1998. 315 p.

KAMP, I. van; LEIDELMEIJER, G. M.; HOLLANDER, A. Urban environmental quality and human well-being: towards a conceptual framework and demarcation of concepts; a literature study. In: Landscape and Urban Planning, Amsterdã, v. 65, n. 1-2, p. 5-18, 2003. Disponível em: <http://www.sciencedirect.com/science/article/pii/S0169204602002323>.

Acesso em: 12 abr. 2012.

LANG, S.; BLASCHKE, T. Análise da paisagem com SIG. Tradução: Hermann Kux. São Paulo: Oficina de Textos, 2009. 424p.

MARTINELLI, P. Qualidade ambiental urbana em cidades médias: proposta de modelo de avaliação para o Estado de São Paulo. 2004. 130 f. Dissertação (Mestrado em Geografia) - Instituto de Geociências e Ciências Exatas, Universidade Estadual Paulista, Rio Claro.

MENDONÇA, J. G. de. Plano diretor, gestão urbana e descentralização: novos caminhos, novos debates. In: FERNANDES, E. (Org.). Direito urbanístico e política urbana no Brasil. Belo Horizonte: Del Rey, 2001. p. 151-164.

MINAKI, M. As praças públicas de Araçatuba-SP: análise de um indicador da qualidade ambiental urbana. 2007. 202 f. Dissertação (Mestrado em Geografia) - Faculdade de Ciências e Tecnologia, Universidade Estadual Paulista, Presidente Prudente.

MONTEIRO, C. A. de F. Geossistemas: a história de uma procura. São Paulo: Contexto, 2000. 127p.

MORATO, R. G.; KAWAKUBO, F. S.; LUCHIARI, A. Geografia da desigualdade ambiental na Subprefeitura de Campo Limpo, município de São Paulo-SP. In: Simpósio Brasileiro de Sensoriamento Remoto, 12. , 2005, Goiânia. Anais... Goiânia: INPE, 2005. p. 2281-2288.

NEGREIROS, R.; SANTOS, S. M. dos. Dificuldades da gestão pública do uso do solo. In: FERNANDES, E. (Org.). Direito urbanístico e política urbana no Brasil. Belo Horizonte: Del Rey, 2001. p. 129-150. 
NUCCI, J. C. Aspectos teóricos do Planejamento da Paisagem. In: NUCCI, J. C. (Org.). Planejamento da Paisagem como subsídio para a participação popular no desenvolvimento urbano. Estudo aplicado ao bairro de Santa Felicidade - Curitiba/PR. Curitiba: LABS/DGEOG/UFPR, 2010. p. 14-25. Disponível em: <www.geografia.ufpr.br/laboratorios/labs/?pg=publicacoesphp>. Acesso em: 08 abr. 2012.

Qualidade Ambiental e Adensamento: um estudo de Planejamento da Paisagem do distrito de Santa Cecília (MSP). 2. ed. Curitiba: Edição do Autor, 2008. 150p.

PAULA, A. S. de. Noções gerais do que seja um Plano Diretor. In: PAULA, A. S. de. (Org.). Estatuto da cidade e o plano diretor municipal. São Paulo: Lemos e Cruz, 2007. p. 17-25.

PEREIRA, R. de M. A proteção jurídica dos recursos hídricos: aspectos legais e práticos. In: BENJAMIN, A. H. de V. e. (Org.). Manual prático da Promotoria de Justiça do estado de São Paulo. 2. ed. São Paulo: IMESP, 1999. p. 247260.

ROCHA, J. R.; FIGUEIRÓ, A. S. Poluição do ar no bairro Centro de Santa Maria/RS: variáveis geourbanas e geocológicas. Mercator, Fortaleza, v. 9, n. 18, p. 105-120, jan-abr. 2012. Disponível em: <http://www.mercator.ufc.br/index.php/mercator/article/view/316/277>. Acesso em: 20 fev. 2012.

SALINAS CHÁVEZ, E.; MIDDLETON, J. La ecología del paisaje como base para el desarrollo sustentable en América Latina. 1998. Disponível em: <http://www.brocku.ca/epi/lebk/lebk.html>. Acesso em: 28 fev. 2008

TUCCI, C. E. M. Drenagem urbana. In: Ciência e Cultura, São Paulo, v. 55, n. 4, out-dez. 2003. Disponível em: <http://cienciaecultura.bvs.br/scielo.php?script=sci_artttext\&pid+S000967252003000400020>. Acesso em: 05 mai. 2009.

. Plano Diretor de Drenagem Urbana: princípios e concepção. In: Revista Brasileira de Recursos Hídricos, Porto Alegre, v. 2, n. 2, p. 05-12, jul-dez. 1997. Disponível em: <http://www.rhama.net/download/artigos/artigo2.pdf>. Acesso em: 05 mai. 2009.

VALASKI, S. Avaliação da qualidade ambiental em condomínios residências horizontais com base nos princípios do planejamento da paisagem. Estudo de caso: bairro Santa Felicidade - Curitiba/PR. 2008. 138 f. Dissertação (Mestrado em Geografia) - Setor de Ciências da Terra, Universidade Federal do Paraná, Curitiba. Disponível em: <http:// www.geografia.ufpr.br/laboratorios/labs/?pg=publicacoes-php>. Acesso em: 10 out. 2010. 